\title{
Prevalence of Obesity and Incidence of Obesity-Related Comorbidities in Koreans Based on National Health Insurance Service Health Checkup Data 2006-2015
}

Mi Hae Seo', Yang-Hyun Kim², Kyungdo Han ${ }^{3}$, Jin-Hyung Jung ${ }^{3}$, Yong-Gyu Park³, Seong-Su Lee ${ }^{4}$, Hyuk-Sang Kwon ${ }^{5}$, Won-Young Lee ${ }^{6, *}$, Soon Jib Yoo ${ }^{4, *}$; on Behalf of the Taskforce Team of the Obesity Fact Sheet of the Korean Society for the Study of Obesity

${ }^{1}$ Division of Endocrinology, Department of Internal Medicine, Soonchunhyang University Gumi Hospital, Soonchunhyang University School of Medicine, Gumi; ${ }^{2}$ Department of Family Medicine, Korea University College of Medicine, Seoul; ${ }^{3}$ Department of Biostatistics, The Catholic University of Korea, Seoul; ${ }^{4}$ Division of Endocrinology and Metabolism, Department of Internal Medicine, Bucheon St. Mary's Hospital, College of Medicine, The Catholic University of Korea, Bucheon; ${ }^{5}$ Division of Endocrinology and Metabolism, Department of Internal Medicine, Yeouido St. Mary's Hospital, College of Medicine, The Catholic University of Korea, Seoul, ${ }^{6}$ Division of Endocrinology and Metabolism, Department of Internal Medicine, Kangbuk Samsung Hospital, Sungkyunkwan University School of Medicine, Seoul, Korea

Background: The prevalence of obesity and related comorbidities is increasing worldwide, including in Korea. The Korean Society for the Study of Obesity released the Obesity Fact Sheet 2017 to address this problem in the Korean population.

Methods: Data from the National Health Insurance Service Health Checkup database from 2006 to 2015 were standardized by age and sex using the 2010 Census. The definition of obesity was a body mass index (BMI) $\geq 25$ $\mathrm{kg} / \mathrm{m}^{2}$, and that of abdominal obesity was a waist circumference $\geq 90 \mathrm{~cm}$ in men and $\geq 85 \mathrm{~cm}$ in women. Multivariate adjusted Cox regression analysis was conducted, and hazard ratios (HRs) with $95 \%$ confidence intervals were calculated for comorbidities.

Results: From 2009 to 2015 , the prevalence of obesity increased from $29.7 \%$ to $32.4 \%$, and that of abdominal obesity increased from $18.4 \%$ to $20.8 \%$. Obesity with abdominal obesity also increased from $15.1 \%$ to $17.7 \%$. Between 2014 and 2015, the prevalence of obesity increased until 30-40 years of age, but decreased from 4050 years of age in men. In women, it increased until the mid-70s, and decreased thereafter. Abdominal obesity increased from 20-30 years of age to 70-80 years of age, but decreased thereafter. The HRs for type 2 diabetes mellitus, hypertension, dyslipidemia, myocardial infarction, and ischemic stroke were elevated in subjects with abdominal obesity, and their incidence increased as the BMl increased, but slowed down at BMI $\geq 35 \mathrm{~kg} / \mathrm{m}^{2}$. Conclusion: Based on the Obesity Fact Sheet 2017, strategies for reducing the prevalence of obesity and abdominal obesity are essential.

Key words: Obesity, Abdominal obesity, Body mass index, Comorbidity, National Health Insurance Service

\author{
Received March 7, 2018 \\ Reviewed March 8, 2018 \\ Accepted March 15, 2018 \\ ${ }^{*}$ Corresponding author \\ Won-Young Lee \\ https://orcid.org/0000-0002-1082-7592 \\ Division of Endocrinology and \\ Metabolism, Department of Internal \\ Medicine, Kangbuk Samsung Hospital, \\ Sungkyunkwan University School of \\ Medicine, 29 Saemunan-ro, Jongno-gu, \\ Seoul 03181, Korea \\ Tel: +82-2-2001-2579 \\ Fax: +82-2-2001-1588 \\ E-mail:drlwy@hanmail.net \\ ${ }^{*}$ Co-Corresponding author \\ Soon Jib Yoo
}

https://orcid.org/0000-0002-9932-4130

Division of Endocrinology and Metabolism, Department of Internal Medicine, Bucheon St. Mary's Hospital, College of Medicine, The Catholic University of Korea, 327 Sosa-ro,

Wonmi-gu, Bucheon 14647, Korea

Tel: +82-32-340-7011

Fax: +82-32-340-2669

E-mail:sjyoo@catholic.ac.kr

The first two authors contributed equally to this study. 


\section{INTRODUCTION}

Globally, the problem of obesity is steadily increasing, and the prevalence of obesity in Korea is also on the rise. ${ }^{1,2}$ The increase in obesity prevalence adds to the socioeconomic burden due to obesity-related comorbidities. ${ }^{3}$ Obesity is a risk factor for cardiometabolic diseases including type 2 diabetes mellitus (T2DM), hypertension (HTN), cardiovascular disease, and some types of cancer. ${ }^{4,5}$

Obesity and weight gain also increase the risk of T2DM, HTN, and cardiovascular diseases by increasing inflammation, which may increase mortality. ${ }^{6-9}$ Obesity-related cancers include colorectal, prostate, and breast cancer, and weight gain is associated with increased cancer-related mortality. ${ }^{10,11}$

Considering the socioeconomic burden of obesity and its association with significant comorbidities, the identification of actionable risk factors would be beneficial for public health. Excess caloric intake and physical inactivity have been identified as risk factors that can be modified by patient action. ${ }^{12}$

In an effort to reduce the prevalence of obesity and examine the risk factors and comorbidities of obesity, the National Health Insurance Service (NHIS) signed a memorandum of understanding with the Korean Society for the Study of Obesity (KSSO) in 2015. In this article, we discuss the prevalence of obesity and related problems according to the 2017 Obesity Fact Sheet, based on NHIS data from 2006 to 2015.

\section{METHODS}

\section{The NHIS database}

The NHIS is a nonprofit, single-payer organization in Korea, and all Koreans must join the NHI. ${ }^{13,14}$ It provides universal coverage for all residents of Korea and pays healthcare providers based on a fee-for-service system. The NHIS obtains patients' demographic information, such as age, sex, region, insurers' payment coverage, medical utilization/transaction information, and deductions and claims data. This database can be used for population-based cohort studies, according to the operational definitions of some diseases. ${ }^{13,15}$

\section{NHI Health Checkup data}

The source population of the NHIS is derived from the Health Insurance Review and Assessment Service. The Health Insurance Review and Assessment database includes data from about 97.0\% of the health insurance claims of the Korean population; details of the NHIS database have been described elsewhere. ${ }^{13}$

The NHIS manages the NHI program, which provides a biannual health checkup program for all insured Koreans, except for employee subscribers who undergo yearly health checkups. The NHI Health Checkup program consists of four areas: general health checkups, cancer checkups, lifetime transition-period health checkups, and baby/infant health checkups. Anthropometric measurements such as weight, height, waist circumference (WC), and systolic and diastolic blood pressure are measured by trained examiners. The NHIS Health Checkup also includes tests for visual and hearing acuity; laboratory tests, such as measurements of fasting blood glucose, total cholesterol, triglyceride, high-density lipoprotein cholesterol, low-density lipoprotein cholesterol, and serum creatinine levels; and urine analysis. Since 2009, the WC has been measured at the level of the umbilicus by trained experts or nurses. In the cancer program, specific cancers are screened: stomach and breast cancer for those aged $\geq 40$ years, colon cancer for those aged $\geq 50$ years, liver cancer for those aged $\geq 40$ years with high risk for hepatic cancer, and cervical cancer for women aged $\geq 30$ years. Each person pays only $10 \%$ of the total cost.

Self-reported questionnaires were administered regarding general health behaviors such as current smoking status, alcohol intake, and regular exercise. The Korean Association of Quality Assurance for Clinical Laboratories warranted the quality of the laboratory tests. The hospitals that performed the health checkups were certified by the NHIS. We used the NHIS Health Checkup database between 2006 and 2015 to select subjects older than 20 years who had undergone health checkups.

\section{Database population}

We used the NHIS database from 2009 to 2015. In total, 84,690, 131 Koreans who were over the age of 20 (men, 46,147,396; women, $38,542,735)$ participated in the NHI Health Checkup. Deidentified and anonymized data were analyzed for this study. The Institutional Review Board of the Korea National Institute for Bio- 
ethics Policy reviewed and approved the protocol of this study (No. P01-201603-21-005).

\section{Definitions of comorbidities and socioeconomic status}

T2DM was defined as a fasting plasma glucose level $\geq 126 \mathrm{mg} / \mathrm{dL}$ (from the NHIS Health Checkup) or at least one claim per year for an antidiabetic medication prescription under the 10th revision of International Classification of Diseases (ICD-10) codes E11-E14. HTN was defined as a blood pressure $\geq 140 / 90 \mathrm{mmHg}$ or at least one claim per year for an antihypertensive medication prescription under ICD-10 codes I10-I15. Dyslipidemia was defined as a total cholesterol level $\geq 240 \mathrm{mg} / \mathrm{dL}$ or at least one claim per year for an antihyperlipidemic medication prescription under ICD-10 code E78. Cardiovascular disease was identified when the subject gave an affirmative answer to the following question: "Do you have a history of stroke or acute myocardial infarction (MI)?" Income was divided into quartiles (Q): Q1 (the lowest), Q2, Q3, and Q4 (the highest). Postmenopausal status was assumed after 50 years of age, as this is the usual age of onset of menopause among Korean women. ${ }^{16}$

\section{Definitions of obesity, abdominal obesity, and class I, II, and III obesity}

Obesity was defined as a body mass index (BMI, which is calculated as the weight $[\mathrm{kg}]$ divided by the square of the height $[\mathrm{m}]$ ) $\geq 25.0 \mathrm{~kg} / \mathrm{m}^{2}$ in adults, in accordance with the Asia-Pacific criteria of the World Health Organization guidelines. ${ }^{17}$ Abdominal obesity was defined as a WC $\geq 90 \mathrm{~cm}$ in men and $\geq 85 \mathrm{~cm}$ in women, in accordance with the definition by the KSSO.$^{18}$ Class I obesity was defined as BMI $\geq 25 \&<30 \mathrm{~kg} / \mathrm{m}^{2}$, class II obesity was defined as BMI $\geq 30 \&<35 \mathrm{~kg} / \mathrm{m}^{2}$, and class III obesity was defined as BMI $\geq 35 \mathrm{~kg} / \mathrm{m}^{2}$.

\section{Statistical analysis}

All analyses were performed separately, with analysis groups. The prevalence and incidence rate data were presented with age and sex standardization using the 2010 Census Korean population. Multivariate adjusted Cox regression analysis was conducted to calculate hazard ratios (HR) with 95\% confidence intervals (CI) for comorbidities such as T2DM, HTN, dyslipidemia, MI, and ischemic stroke after adjustment for age and sex. All statistical analyses were performed with SAS version 9.3 (SAS Institute Inc., Cary, NC, USA).

\section{RESULTS}

\section{Obesity prevalence trends by sex and age}

The prevalence of obesity steadily increased from $29.7 \%$ in 2009 to $32.4 \%$ in 2015 , and that of abdominal obesity increased from $18.4 \%$ in 2009 to $20.8 \%$ in 2015 (Fig. 1A, B). The prevalence of obesity with abdominal obesity increased steadily from $15.1 \%$ in 2009 to $17.7 \%$ in 2015 (Fig. 1C).

Fig. 2 displays the prevalence of obesity and abdominal obesity by age group between 2014 and 2015. In men, the prevalence of obesity increased until the age of 30 years, but decreased from 4050 years of age. In women, however, it increased until the mid-70s, and decreased thereafter (Fig. 2A). Abdominal obesity by age group increased steadily from 20-30 years of age to 70-80 years of age in total, but decreased after 80 years of age. Before 60-70 years of age, the prevalence of abdominal obesity was higher in men than in women, but after 60-70 years of age, it was higher in women than in men (Fig. 2B).

\section{BMI and five comorbidities based on the presence of abdominal obesity}

The HRs for T2DM, HTN, dyslipidemia, MI, and ischemic stroke are presented in Table 1. Compared to subjects with normal BMI $\left(18.5-23 \mathrm{~kg} / \mathrm{m}^{2}\right)$ without abdominal obesity, subjects with abdominal obesity had increased HRs for the five comorbidities. The HRs for the five comorbidities increased as the BMI increased, but the HRs for MI and stroke were also greater in underweight subjects than in those of normal weight.

\section{BMI increases and the incidence rates of T2DM, HTN, and dyslipidemia}

Fig. 3 displays the incidence rates of T2DM, HTN, and dyslipidemia in relation to increases in BMI. The incidences of T2DM, HTN, and dyslipidemia increased gradually as the BMI increased from the lowest level. For T2DM and HTN, the increases in the incidence rates slowed down around BMI $\geq 35 \mathrm{~kg} / \mathrm{m}^{2}$, while for dyslipidemia, the incidence rate slowed down at BMI $\geq 37 \mathrm{~kg} / \mathrm{m}^{2}$. 

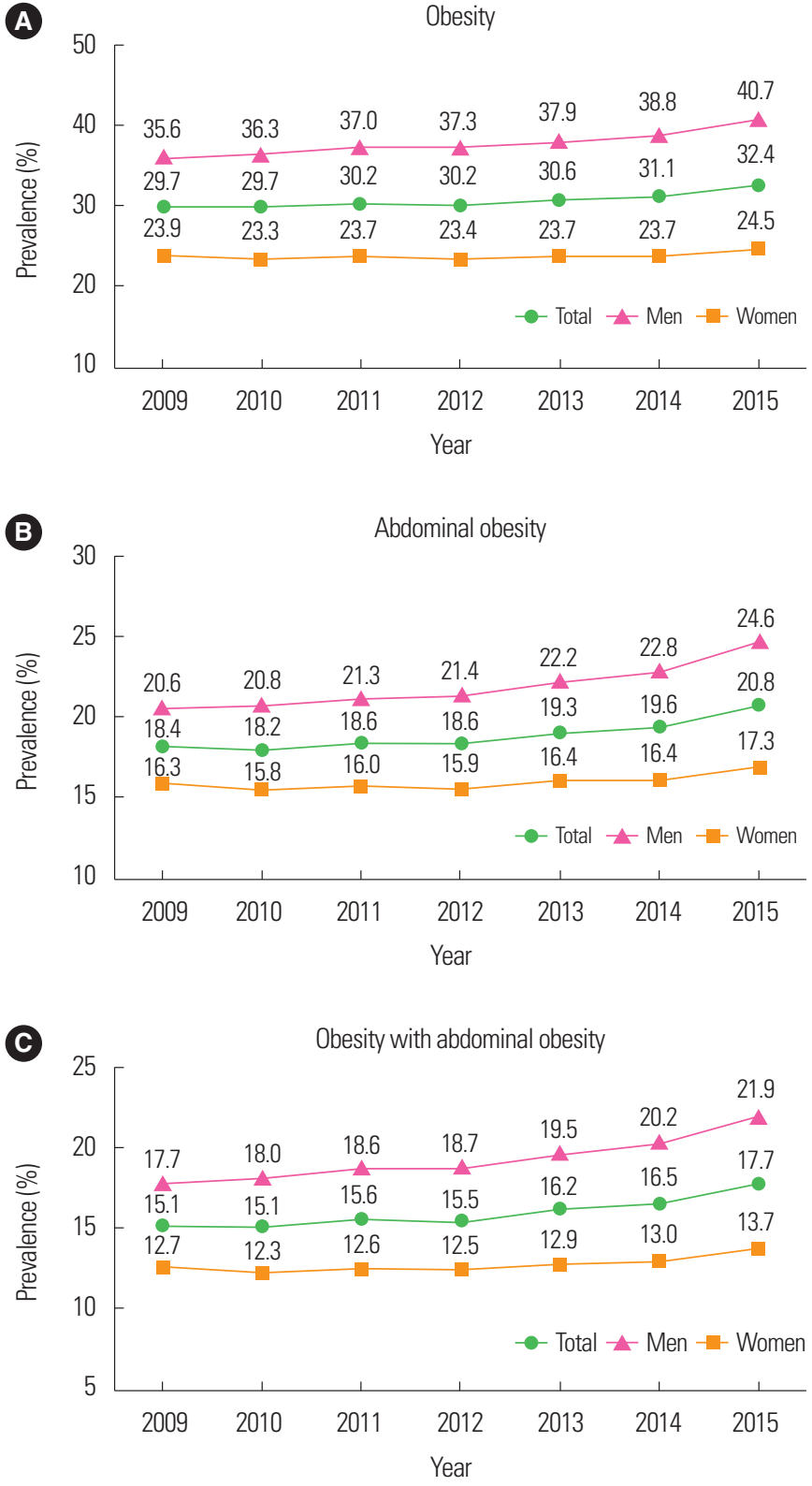

Figure 1. The prevalence of obesity (A), abdominal obesity (B), and obesity with abdominal obesity (C) between 2009 and 2015. Data derived from the National Health Insurance Service data set: 2009-2015. Data are presented with age and sex standardization using the 2010 Census Korean population. The definition of obesity is $\mathrm{BMl} \geq 25 \mathrm{~kg} / \mathrm{m}^{2}$, and that of abdominal obesity is a waist circumference $\geq 90 \mathrm{~cm}$ in men and $\geq 85 \mathrm{~cm}$ in women.

\section{DISCUSSION}

In this study, we found that the prevalence of obesity, abdominal obesity, and obesity with abdominal obesity steadily increased from 2009 to 2015, and this increase was more prominent in men
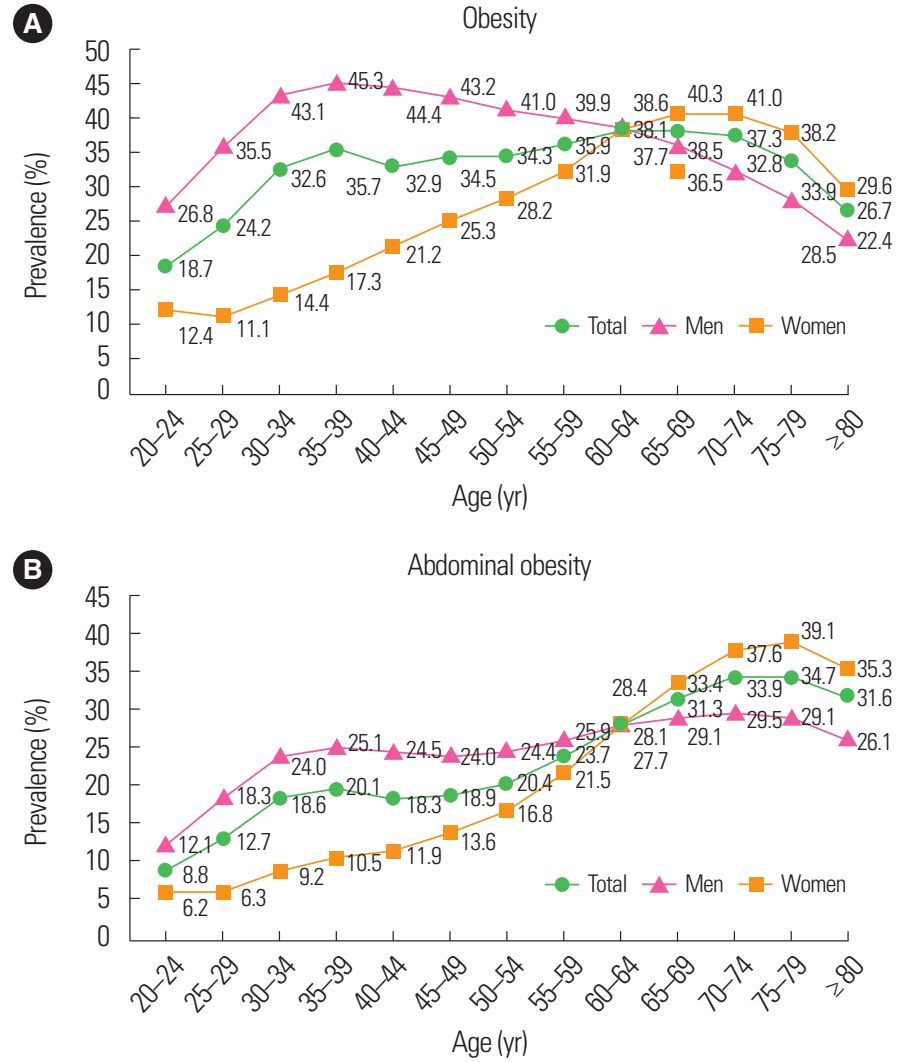

Figure 2. The prevalence of obesity $(A)$ and abdominal obesity (B) by age group between 2014 and 2015. Data derived from the National Health Insurance Service data set: 2014-2015. Data are presented with age and sex standardization using the 2010 Census Korean population. The definition of obesity is BMl $\geq 25 \mathrm{~kg} / \mathrm{m}^{2}$, and that of abdominal obesity is a waist circumference $\geq 90 \mathrm{~cm}$ in men and $\geq 85$ $\mathrm{cm}$ in women.

Table 1. The hazard ratios for T2DM, HTN, dyslipidemia, MI, and ischemic stroke according to BMl and abdominal obesity

\begin{tabular}{lcccccc}
\hline $\begin{array}{l}\text { BMl } \\
\left(\mathrm{kg} / \mathrm{m}^{2}\right)\end{array}$ & $\begin{array}{c}\text { Abdominal } \\
\text { obesity }\end{array}$ & T2DM & HTN & Dyslipidemia & Ml & Stroke \\
\hline$<18.5$ & No & $0.762^{*}$ & $0.681^{*}$ & $0.514^{*}$ & $1.203^{*}$ & 1.004 \\
& Yes & 1.094 & 1.009 & $0.575^{*}$ & $1.719^{*}$ & 1.079 \\
$18.5-23$ & No & 1 & 1 & 1 & 1 & 1 \\
& Yes & $1.778^{*}$ & $1.373^{*}$ & $1.185^{*}$ & $1.384^{*}$ & $1.316^{*}$ \\
$23-25$ & No & $1.665^{*}$ & $1.451^{*}$ & $1.495^{*}$ & $1.050^{*}$ & $1.015^{*}$ \\
& Yes & $2.434^{*}$ & $1.674^{*}$ & $1.635^{*}$ & $1.283^{*}$ & $1.223^{*}$ \\
$25-30$ & No & $2.499^{*}$ & $1.963^{*}$ & $1.824^{*}$ & $1.166^{*}$ & $1.061^{*}$ \\
& Yes & $3.638^{*}$ & $2.328^{*}$ & $2.076^{*}$ & $1.337^{*}$ & $1.241^{*}$ \\
$\geq 30$ & No & $4.807^{*}$ & $2.992^{*}$ & $2.251^{*}$ & $1.603^{*}$ & $1.238^{*}$ \\
& Yes & $7.170^{*}$ & $3.796^{*}$ & $2.712^{*}$ & $1.668^{*}$ & $1.439^{*}$ \\
\hline
\end{tabular}

Data derived from the National Health Insurance Service data set: 2009-2015. The definition of obesity is $\mathrm{BMl} \geq 25 \mathrm{~kg} / \mathrm{m}^{2}$, and that of abdominal obesity is a waist circumference $\geq 90 \mathrm{~cm}$ in men and $\geq 85 \mathrm{~cm}$ in women.

${ }^{*} P$-value $<0.05$.

T2DM, type 2 diabetes mellitus; HTN, hypertension; Ml, myocardial infarction; BMI, body mass index. 


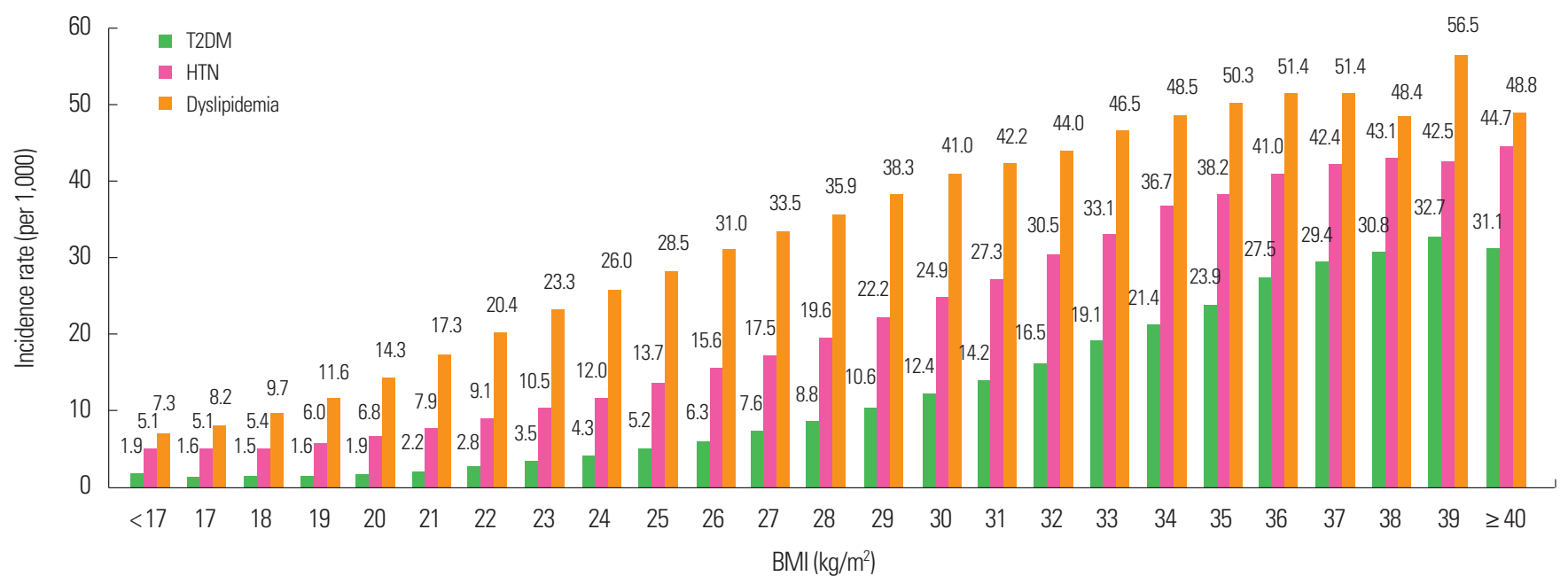

Figure 3. Body mass index (BMI) and the incidence rates of type 2 diabetes mellitus (T2DM), hypertension (HTN), and dyslipidemia. Data derived from the National Health Insurance Service data set: 2009-2015. Data are presented with age and sex standardization using the 2010 Census Korean population. The definition of obesity is BMI $\geq 25 \mathrm{~kg} / \mathrm{m}^{2}$, and that of abdominal obesity is a waist circumference $\geq 90 \mathrm{~cm}$ in men and $\geq 85 \mathrm{~cm}$ in women.

than in women. The prevalence of obesity increased until the age of 30 years in men, but increased until the mid-70s in women. Unlike the prevalence of obesity, the prevalence of abdominal obesity steadily increased with age in both men and women. The HRs for comorbidities were higher in subjects with abdominal obesity, and the incidence rates for T2DM and HTN increased as the BMI increased, but slowed down at BMI $\geq 35 \mathrm{~kg} / \mathrm{m}^{2}$.

Obesity increases the risk of T2DM, HTN, and cardiovascular disease risk factors. ${ }^{6,7}$ Indonesians (Malay and Chinese ancestry), Singaporean Chinese, Malays, Indians, and Hong Kong Chinese (roughly all Asian populations studied) were reported to have higher body fat percentages at lower BMI than Caucasians. Generally, for the same BMI, the body fat percentages in these populations were $3 \%-5 \%$ higher than those of Caucasians. ${ }^{19}$ Thus, it was suggested that the association between BMI and percentage of body fat is different in the Asian population than in the Western population..$^{20} \mathrm{Oh}$ et al. ${ }^{20}$ reported a cohort study of 773,915 Korean men and women between 30 and 59 years of age, with 8- to 10year follow-up periods, and suggested that populations with BMI $\geq 25 \mathrm{~kg} / \mathrm{m}^{2}$ are rapidly increasing and are at substantial risk for diseases. In this study, the BMI ranges corresponding to different relative risks of HTN were demonstrated. BMIs of 24-25, 27-28, and $31-32 \mathrm{~kg} / \mathrm{m}^{2}$ in men and BMIs of $23-24,26-27$, and $29-30 \mathrm{~kg} / \mathrm{m}^{2}$ in women corresponded to HRs of $1.5,2.0$, and 2.5, respectively. For hypercholesterolemia, however, BMI of $25-26 \mathrm{~kg} / \mathrm{m}^{2}$ corre- sponded to an HR of 1.5 in both men and women. For T2DM, the BMI categories of $23-24,25-26,26-27$, and $27-28 \mathrm{~kg} / \mathrm{m}^{2}$ in men and of $22-23,23-24,24-25$, and $25-26 \mathrm{~kg} / \mathrm{m}^{2}$ in women corresponded approximately to HRs of 1.5, 2.0, 2.5, and 3.0, respectively. Women had higher HRs for diabetes than men at each BMI lev$\mathrm{el}^{20}$

According to the 2017 Obesity Fact Sheet, the incidence rates of T2DM, HTN, and dyslipidemia increased continuously as the BMI increased from 17 to $35 \mathrm{~kg} / \mathrm{m}^{2}$. In particular, T2DM, HTN, and dyslipidemia increased significantly at BMI above $25 \mathrm{~kg} / \mathrm{m}^{2}$, which is also the diagnostic criterion for obesity of the KSSO. Furthermore, men with $\mathrm{WC} \geq 90 \mathrm{~cm}$ and women with $\mathrm{WC} \geq 85 \mathrm{~cm}$ (abdominal obesity) were at high risk for T2DM, HTN, and dyslipidemia. The occurrence of these comorbidities increased at BMIs around $23,25,30$, and $35 \mathrm{~kg} / \mathrm{m}^{2}$. These findings support the current obesity diagnostic criteria of the KSSO and the obesity treatment guidelines. We calculated the first and second cutoff points for increasing HRs for one of the three comorbidities (T2DM, HTN, and dyslipidemia). The first cutoff BMI level was $23 \mathrm{~kg} / \mathrm{m}^{2}$, and the second cutoff BMI level was $25 \mathrm{~kg} / \mathrm{m}^{2}$ (data not shown).

In addition, the prevalence of $\mathrm{MI}$ increased at $\mathrm{BMI} \geq 23 \mathrm{~kg} / \mathrm{m}^{2}$. These results demonstrate that Asians, in particular Koreans, have a higher disease risk than Western people at relatively low BMI. Further precise and well-designed studies are needed to develop 
strategies to reduce the prevalence of obesity.

There are some limitations to this study. First, the NHIS Health Checkup data consist only of income data, which limits the evaluation of the association between socioeconomic status and obesity. On the other hand, the Korea National Health and Nutrition Examination Survey has information about educational level and income, and could be an alternative for evaluation. Second, there are discrepancies between the claim database and the disease diagnoses in real world although we used operational definitions of each disease. Third, the NHI Health Checkup data only include subjects aged $>20$ years, so we could not obtain the prevalence of obesity in children and adolescents. However, the strengths of this study are that the real prevalence of obesity was demonstrated among all the members of the Korean population who underwent the NHIS Health Checkup, and the incidence rates of T2DM, HTN, and dyslipidemia at BMI $\geq 30 \mathrm{~kg} / \mathrm{m}^{2}$ were identified.

In conclusion, based on information from the Obesity Fact Sheet 2017, the prevalence of obesity is rapidly increasing in Korea. It is essential to develop policies and support systems to reduce the prevalence of obesity and obesity-related comorbidities. Further studies are needed to investigate other aspects of obesity status to establish evidence for policy.

\section{CONFLICTS OF INTEREST}

The authors declare no conflict of interest.

\section{ACKNOWLEDGMENTS}

We thank the National Health Insurance Service and the Korean Society for the Study of Obesity.

This study was supported by a grant from the Korean Health Technology and R\&D project, Ministry of Health \& Welfare, Republic of Korea (HC16C2285).

\section{REFERENCES}

1. Ng M, Fleming T, Robinson M, Thomson B, Graetz N, Margono $\mathrm{C}$, et al. Global, regional, and national prevalence of overweight and obesity in children and adults during 1980-
2013: a systematic analysis for the Global Burden of Disease Study 2013. Lancet 2014;384:766-81.

2. Kang HT, Shim JY, Lee HR, Park BJ, Linton JA, Lee YJ. Trends in prevalence of overweight and obesity in Korean adults, 19982009: the Korean National Health and Nutrition Examination Survey. J Epidemiol 2014;24:109-16.

3. Wyatt SB, Winters KP, Dubbert PM. Overweight and obesity: prevalence, consequences, and causes of a growing public health problem. Am J Med Sci 2006;331:166-74.

4. Mokdad AH, Ford ES, Bowman BA, Dietz WH, Vinicor F, Bales VS, et al. Prevalence of obesity, diabetes, and obesity-related health risk factors, 2001. JAMA 2003;289:76-9.

5. Yoon KH, Lee JH, Kim JW, Cho JH, Choi YH, Ko SH, et al. Epidemic obesity and type 2 diabetes in Asia. Lancet 2006; 368:1681-8.

6. Ford ES, Williamson DF, Liu S. Weight change and diabetes incidence: findings from a national cohort of US adults. Am J Epidemiol 1997;146:214-22.

7. Huang Z, Willett WC, Manson JE, Rosner B, Stampfer MJ, Speizer FE, et al. Body weight, weight change, and risk for hypertension in women. Ann Intern Med 1998;128:81-8.

8. Fogarty AW, Glancy C, Jones S, Lewis SA, McKeever TM, Britton JR. A prospective study of weight change and systemic inflammation over 9 y. Am J Clin Nutr 2008;87:30-5.

9. Kim YH, Kim SM, Han KD, Son JW, Lee SS, Oh SW, et al. Change in weight and body mass index associated with allcause mortality in Korea: a nationwide longitudinal study. J Clin Endocrinol Metab 2017;102:4041-50.

10. Playdon MC, Bracken MB, Sanft TB, Ligibel JA, Harrigan M, Irwin ML. Weight gain after breast cancer diagnosis and allcause mortality: systematic review and meta-analysis. J Natl Cancer Inst 2015;107:djv275.

11. Bonn SE, Wiklund F, Sjolander A, Szulkin R, Stattin P, Holmberg $\mathrm{E}$, et al. Body mass index and weight change in men with prostate cancer: progression and mortality. Cancer Causes Control 2014;25:933-43.

12. Armstrong AC, Evans GD. Management of women at high risk of breast cancer. BMJ 2014;348:g2756.

13. Song SO, Jung CH, Song YD, Park CY, Kwon HS, Cha BS, et al. Background and data configuration process of a nationwide 
population-based study using the Korean National Health Insurance system. Diabetes Metab J 2014;38:395-403.

14. National Health Insurance Service. National Health Insurance Service: Health Checkup [Internet]. Wonju: National Health Insurance Service; 2018 [cited 2018 Mar 19]. Available from: https://www.nhis.or.kr/static/html/wbd/g/a/wbdga0606.html

15. Kim YH, Han K, Son JW, Lee SS, Oh SW, Kwon HS, et al. Data analytic process of a nationwide population-based study on obesity using the national health information database presented by the National Health Insurance Service 2006-2015. J Obes Metab Syndr 2017;26:23-7.

16. Lim HS, Kim TH, Lee HH, Park YH, Kim JM, Lee BR. Hypertension and age at onset of natural menopause in Korean postmenopausal women: results from the Korea National Health and Nutrition Examination Survey (2008-2013). Ma- turitas 2016;90:17-23.

17. World Health Organization; Regional Office for the Western Pacific. The Asia-Pacific perspective: redefining obesity and its treatment. Sydney: Health Communications Australia; 2000.

18. Lee SY, Park HS, Kim DJ, Han JH, Kim SM, Cho GJ, et al. Appropriate waist circumference cutoff points for central obesity in Korean adults. Diabetes Res Clin Pract 2007;75:72-80.

19. Deurenberg P, Deurenberg-Yap M, Guricci S. Asians are different from Caucasians and from each other in their body mass index/body fat per cent relationship. Obes Rev 2002;3: 141-6.

20. Oh SW, Shin SA, Yun YH, Yoo T, Huh BY. Cut-off point of BMI and obesity-related comorbidities and mortality in middle-aged Koreans. Obes Res 2004;12:2031-40. 